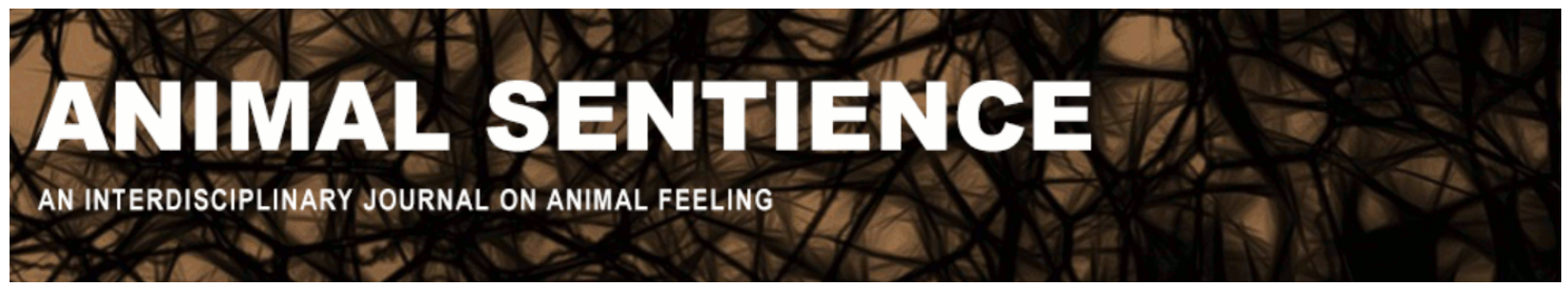

Benz-Schwarzburg, Judith (2018) We don't want to know what we know. Animal Sentience 23(12)

DOI: $10.51291 / 2377-7478.1397$

Date of submission: 2019-02-03

Date of acceptance: 2019-02-11

(c)

This article has appeared in the journal Animal

Sentience, a peer-reviewed journal on animal

cognition and feeling. It has been made open access,

free for all, by WellBeing International and deposited

in the WBI Studies Repository. For more information,

please contact

wbisr-info@wellbeingintl.org.

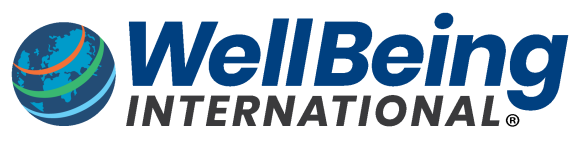

SOLUTIONS FOR PEOPLE, ANIMALS AND ENVIRONMENT 


\title{
We don't want to know what we know
}

Commentary on Chapman \& Huffman on Human Difference

\author{
Judith Benz-Schwarzburg \\ Unit of Ethics and Human-Animal Studies, Messerli Research Institute \\ University of Veterinary Medicine Vienna, University of Vienna, Medical University Vienna
}

\begin{abstract}
Why are humans so ignorant with regard to the fundamental gap between ethical claims and the status quo of the human-animal relationship? To answer this, we should include more psychological and sociological perspectives in our discussions.
\end{abstract}

Judith Benz-Schwarzburg is a Senior Researcher at the Unit for Ethics and Human-Animal Studies at the Messerli Research Institute, Vienna. She is PI of a research group on Morality in Animals. Her work focuses on sociocognitive abilities in animals and their ethical relevance. Website

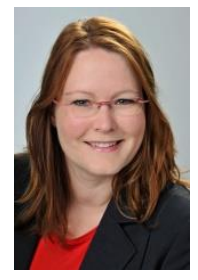

Many scholars are leaving the comfort zone of a (supposedly) purely scientific research interest in the animal mind and starting to discuss the ethical implications of our growing knowledge in this field (see e.g., Benz-Schwarzburg \& Knight 2011, Benz-Schwarzburg \& Benz 2012, DeGrazia 1996, Bekoff \& Allen 2007). Missing empirical evidence on the complex cognitive, social, and emotional abilities as well as the needs of animals is no longer a sufficient explanation of why humans treat animals in an ethically unjustifiable way. The evidence Chapman \& Huffman (2018) (C \& H) provide spans nonhuman animals' capacity to use tools and medicine, build complex constructions and solve problems (e.g., using outstanding working memory capacity for remembering numbers). We can easily add studies from all other areas of complex social, cognitive, or emotional capacity to this picture.

Even moral abilities are no longer untouched by research: capuchin monkeys are sensitive to others' welfare (Lakshminarayanan et al. 2008), great apes show altruistic helping (Warneken \& Tomasello 2006), and rats are capable of empathically motivated pro-social behaviour (Bartal et al. 2011). Ravens show consolation behaviour (Fraser et al. 2010) as much as bonobos, elephants and prairie-voles console and reassure others in distress (Clay \& de Waal 2013, Plotnik \& de Waal 2014, Burkett et al. 2016). Consolation, reconciliation and third-party affiliation have also been found in budgerigars (Ikkatai 2016). And dogs as well as rats show inequity aversion (Range et al. 2009, Oberliessen et al. 2016) - This is just to mention a few domains of complex moral capacities, only a few studies within these domains, and only a few species that have been studied. We have also started to investigate what it means for the way we treat them if they share such moral capacities with us (Monsó et al. 2018).

The results from the labs and field stations engaged in research on comparative cognition clearly reach the public. The ape mastering the memory test by Inoue \& Matsuzawa (2007) was all over the news, and when Pepperberg's parrot Alex died, the press from the New York Times to the Economist highlighted his outstanding contribution to research. Jay Leno's Tonight Show reported on his death, the news was everywhere from CBS to CNN. International attention and condolence reached the level of thousands of mails per day; the Alex Foundation 
set up a condolence page, and Diane Sawyer from Good Morning America announced: "And now I have a kind of obituary and I want to inform the next of kin about a death in the family. And, yes, the next of kin would be all of us" (Pepperberg 2008: pp. 1-7). This means: knowing about the complex abilities of animals shouldn't be a problem.

Maybe people don't know that we inflict on animals the "atrocities" and "cruelty" to which C \& H refer. But ethicists, welfare scientists, veterinarians and animal advocates have pointed these out for decades. Again, the media covers issues like animal testing, the killing of male chicks, the transportation of farm animals to slaughterhouses, the welfare of zoo animals and so on. We have the ethical arguments available, ready to use, ranging from the principle of non-maleficence, which asks us to avoid unnecessary harm, to the main arguments of animal rights theory (like the argument from personhood, nicely summarized by Andrews et al. 2019). The fact that we know about the animals' complex abilities and needs and about the atrocious treatment they receive is surely also true in the case of farm animals, the group of animals which we use most intensively in terms of numbers (Nawroth et al., forthcoming). And last, we clearly know about all the environmental problems - such as climate change, deforestation or waste of fresh water - that come with our use of animals and animal products.

It seems that we do not want to know. To understand this, we need to factor in the psychological phenomenon of cognitive dissonance (Zentall 2017). Let's stick with the human choice "to eat higher up on the food chain" ( $C \& \mathrm{H}$, p. 5). Many people like eating meat, but don't want to hurt creatures that have minds. Meat-eaters find themselves faced with the socalled "meat paradox," defined as the inconsistency between the appreciation for animals and the enjoyment of consuming their flesh (Bastian et al. 2012). They deal with this dilemma by a number of dissonance-relieving strategies. The denial of morally relevant qualities, specifically the denial of complex cognitive capacities and suffering in animals, has been found to be a "particularly useful strategy" whenever people want to reduce the conflict of the meat paradox. Empirical studies support this claim (Bilewicz et al. 2011; Bratanova et al. 2011; Loughnan et al. 2010). Farm animals are rated significantly lower with regard to complex cognition but significantly higher with regard to edibility than wild animals and companion animals. In Europe and America, dogs and great apes are rated high in cognitive abilities and low in edibility (Bastian et al. 2012, Fig. 9: p. 249). According to Bastian et al. (2012: p. 247), we should investigate meat consumption as a moral choice because this could provide insights into how cognitive and motivational processes obscure moral responsibility.

Biologists and ethicists alone are stuck when it comes to cognitive and motivational processes. Social and cognitive psychologists should be encouraged to contribute more to our research on the human-animal relationship. Sociologists too. Treatment of animals that ethicists find problematic is often widely accepted in society, even supported and reinforced (Joy 2011).

So, $\mathrm{C} \& \mathrm{H}$ are right. We still evaluate most animals on the basis of what they provide to us. We should worry about all the obviously morally problematic ways we treat them. Even more troublesome are the forms of treatment that most people find less obviously problematic: Most people believe meat consumption is natural, normal, and necessary (Joy 2011: p. 96). How can we ever come to recognize animals as kin and show them the respect and kindness they deserve as long as our perception of them is grounded in such unquestioned social beliefsystems? All the relevant disciplines need to converge and collaborate on this pressing moral problem. 


\section{References}

Allen, C., and Bekoff, M. (2007) Animal minds, cognitive ethology, and ethics. The Journal of Ethics 11(3), 299-317.

Andrews et al. (2019) Chimpanzee rights: The philosophers' brief. New York: Routledge.

Bartal, I. B.-A., Decety, J., and Mason, P. (2011) Empathy and pro-social behavior in rats. Science 334 (6061): 1427-1430.

Bastian, B., Loughnan, S., Haslam, and Radke, H. R. M. (2012) Don't mind meat? The denial of mind to animals used for human consumption. Personality and Social Psychology Bulletin 38(2), 247-256.

Benz-Schwarzburg, J., and Benz, S. (2012) Driving the great apes to extinction: Perspectives from conservation biology, politics and bioethics. In: A. Somit and S. A. Peterson (eds.), Biopolicy: The life sciences and public policy. Bingley, U.K.: Emerald Books, pp. 179-210.

Benz-Schwarzburg, J., and Knight, A. (2011) Cognitive relatives yet moral strangers? Journal of Animal Ethics 1, 1-36.

Bilewicz, M., Imhoff, R., and Drogosz, M. (2011) The humanity of what we eat: Conceptions of human uniqueness among vegetarians and omnivores. European Journal of Social Psychology 41, 201-209.

Bratanova, B., Loughnan, S., and Bastian, B. (2011) The effect of food categorization on the perceived moral standing of animals. Appetite 57, 193-196.

Burkett, J. P., Andari, E., Johnson, Z. V., Curry, D. C., de Waal, F. B. M., and Young, L. J. (2016) Oxytocin-dependent consolation behavior in rodents. Science 351(6271), 375-378.

Chapman, C. A., and Huffman, M. A. (2018) Why do we want to think humans are different? Animal Sentience 23(1).

Clay, Z., and de Waal, F. B. M. (2013) Bonobos respond to distress in others: Consolation across the age spectrum. PLoS ONE 8(1), e55206.

DeGrazia, D. (1996) Taking animals seriously: Mental life and moral status. Cambridge: Cambridge University Press.

Fraser, O. N., and Bugnyar, T. (2010) Do ravens show consolation? Responses to distressed others. PLoS ONE 5(5), e10605.

Ikkatai, Y., Watanabe, S., and Izawa, E-I. (2016) Reconciliation and third-party affiliation in pairbond budgerigars (Melopsittacus Undulatus). Behaviour 153(9-11), 1173-1193.

Inoue, S., and Matsuzawa, T. (2007) Working memory of numerals in chimpanzees. Current Biology 17, R1004-R1005.

Joy, M. (2011) Why we love dogs, eat pigs, and wear cows: An introduction to carnism. Conari, San Francisco.

Lakshminarayanan, V. R., and Santos, L. R. (2008) Capuchin monkeys are sensitive to others' welfare. Current Biology 18(21), R999-R1000.

Loughnan, S., Haslam, N., and Bastian, B. (2010) The role of meat consumption in the denial of moral status and mind to meat animals. Appetite 55, 156-159.

Monsó, S., Benz-Schwarzburg, J., and Bremhorst, A. (2018) Morality in animals: What it means and why it matters. Journal of Ethics 22(3), 283-310. 
Nawroth, C., Langbein, J., Coulon, M., Gabor, V., Oesterwind, S., Benz-Schwarzburg, J., and von Borell, E. (Forthcoming) Farm animal cognition: Linking behaviour, welfare and ethics. Frontiers in Veterinary Science 6, 24.

Oberliessen, L., Hernandez-Lallement, J., Schäble, S., van Wingerden, M., Seinstra, M., and Kalenscher, T. (2016) Inequity aversion in rats, Rattus norvegicus. Animal Behaviour 115, 157-166.

Pepperberg, I. (2008) Alex \& me. New York: Harper Collins.

Plotnik, J. M., and de Waal, F. B. M. (2014) Asian elephants (Elephas Maximus) reassure others in distress. PeerJ.

Range, F., Horn, L., Viranyi, Z., and Huber, L. (2009) The absence of reward induces inequity aversion in dogs. PNAS 106(1), 340-345.

Warneken, F., and Tomasello, M. (2006) Altruistic helping in human infants and young chimpanzees. Science 311(5765), 1301-1303.

Zentall, T. R. (2016) Cognitive dissonance or contrast? Animal Sentience 12(1). 